\title{
Effects of Heat Treatment on the Morphology of Long-Period Stacking Ordered Phase and the Corresponding Damping Capacities of Mg-Cu-Mn-Zn-Y Alloys
}

\author{
Dezhao Qin ${ }^{1}$, Jingfeng Wang ${ }^{1, *}$, Ruopeng $\mathrm{Lu}^{1}$, Yongliang $\mathrm{Chen}^{2}$, She $\mathrm{Ma}^{2}$ and Fusheng Pan ${ }^{1}$ \\ ${ }^{1}$ The State Key Laboratory of Mechanical Transmission, College of Materials Science and Engineering, Chongqing University, \\ Chongqing 400044, P. R. China \\ ${ }^{2}$ Institute of Applied Electronics, China Academy of Engineering Physics, Mianyang 621900, P. R. China
}

\begin{abstract}
Different cooling processes of solid solution treatment, such as quenching in water and cooling in furnace, were introduced to $\mathrm{Mg}-3 \mathrm{Cu}-$ $1 \mathrm{Mn}-1.8 \mathrm{Zn}-10 \mathrm{Y}$ (mass\%) alloy. The morphology of long-period stacking ordered (LPSO) phase and the corresponding damping capacities were investigated in the present study. The block-shaped and the lamellar-shaped LPSO phases can be obtained through different cooling processes. Furthermore, the lamellar-shaped 14H LPSO phase grew and ran through the whole grains. Comparison of the damping capacities of the alloys with different morphologies, it reveals that the lamellar LPSO phases precipitated in the matrix are more conducive to the damping capacity that $Q^{-1} \geq 0.052$ at strains exceeding $1 \times 10^{-3}$. The grain size is almost same and no new phase is found after the processes. Meanwhile, it can conclude that the sample cooled in the furnace exhibits higher damping capacity due to the coarse grains and formation of lamellar-shaped 14H LPSO phase. [doi:10.2320/matertrans.M2015234]
\end{abstract}

(Received June 10, 2015; Accepted September 24, 2015; Published November 9, 2015)

Keywords: magnesium alloys, long-period stacking ordered (LPSO) phase, solid solution treatment, damping properties

\section{Introduction}

Magnesium alloys with excellent damping performance and low density in all of the structural metallic materials have attracted a great deal of attention. ${ }^{1-3)}$ They are suitable for application in the transport or aerospace industry. However, it is believed that the behaviors of pure magnesium and some magnesium alloys conform with the G-L theory. ${ }^{4,5)}$ In this case, the damping capacity of magnesium alloys is closely related to the interaction between the movement of dislocations and point defect, including solute atoms, secondary phases, and point vacancy. Meanwhile, strengthening materials traditionally involves controlled creation of internal defects and boundaries to obstruct dislocation motion. Therefore the secondary phases influence the damping capacity and contribute to damping properties. There are three kinds of ternary equilibrium $\mathrm{Mg}-\mathrm{Zn}-\mathrm{Y}$ phases, the I-phase $\left(\mathrm{Mg}_{3} \mathrm{Zn}_{6} \mathrm{Y}\right.$, quasi-crystal structure), the W-phase $\left(\mathrm{Mg}_{3} \mathrm{Zn}_{3} \mathrm{Y}_{2}\right.$, face-centered cubic structure) and the X-phase $\left(\mathrm{Mg}_{12} \mathrm{ZnY}\right.$, long-period stacking ordered (LPSO) structure) existing in $\mathrm{Mg}-\mathrm{Zn}-\mathrm{Y}-\mathrm{Zr}$ alloy system by adjusting the $\mathrm{Zn} / \mathrm{Y}$ weight ratio. ${ }^{6,7)}$

In recent years, Long Period Stacking Ordered (LPSO) Phase are attractive as the special structure owing to their good characteristics for specific strength and damping capacity, which have a great potential to be used in $\mathrm{Mg}$ $\mathrm{Zn}-\mathrm{RE}$ alloys. LPSO phase in $\mathrm{Mg}-\mathrm{Zn}-\mathrm{RE}$ magnesium alloys can be divided into two types. ${ }^{8)}$ One is kind of like $\mathrm{Mg}-\mathrm{Zn}-\mathrm{Y}$, $\mathrm{Mg}-\mathrm{Zn}-\mathrm{Dy}, \mathrm{Mg}-\mathrm{Zn}-\mathrm{Ho}, \mathrm{Mg}-\mathrm{Zn}-\mathrm{Er}$, and $\mathrm{Mg}-\mathrm{Zn}-\mathrm{Tm}$ alloy which belongs to type I, the LPSO phase formed at the grain boundary as the secondary phase in the process of alloy solidification, its structure is 18R type and could be transformed into $14 \mathrm{H}$ type in the subsequent high temperature heat treatment process. The other one is kind of like $\mathrm{Mg}-\mathrm{Zn}-$ $\mathrm{Gd}$ and $\mathrm{Mg}-\mathrm{Zn}-\mathrm{Tb}$ alloy which belongs to type II, the LPSO phase would not be formed in the solidification process, but

*Corresponding author, E-mail: jfwang@cqu.edu.cn will be precipitated out $14 \mathrm{H}$ type from the supersaturated $\mathrm{Mg}$ substrate in the high temperature annealing process. A. Inoue et $a l .{ }^{9)}$ developed an as-extruded $\mathrm{Mg}_{97} \mathrm{Zn}_{1} \mathrm{Y}_{2}$ alloy reinforced by LPSO phase can obtain a tensile yield strength of $610 \mathrm{MPa}$ which exhibits excellent mechanical properties. Wang et al. ${ }^{10)}$ reported that both the damping capacities and yield strength increased with LPSO phase in the as-cast $\mathrm{Mg}-\mathrm{Cu}-$ $\mathrm{Mn}-\mathrm{Zn}-\mathrm{Y}$ alloy. LPSO phase can offer reinforcement effect to the $\mathrm{Mg}-\mathrm{Zn}-\mathrm{Y}$ alloy owing to their unique crystal structure, high strength and damping and good thermal stability.

K. Sugimoto et al. ${ }^{11)}$ put forward conditions of the high damping magnesium alloys including the primary magnesium grains were dendritic or globular in shape and larger than 10 microns in size. To investigate influence of morphology and distribution of LPSO phase on damping property, using solid solution treatment which can improve the grain size to avoid the grain size is too small to observe. The present work investigates the effects of solid solution treatment followed by quenching in water and cooling in furnace on the microstructure, phase distribution, and corresponding damping properties of $\mathrm{Mg}-3 \mathrm{Cu}-1 \mathrm{Mn}-1.8 \mathrm{Zn}-$ 10Y (mass\%, nominal chemical compositions) series alloys using optical microscopy (OM), X-ray diffraction (XRD), and damping tests (DMA).

\section{Experimental}

The pure magnesium was melted in an electrical furnace using a mild steel crucible under a protective argon atmosphere. $\mathrm{Mg}-30.0 \% \mathrm{Cu}$ (mass\%), Mg-3.2\% Mn (mass \%), $\mathrm{Mg}-25 \% \mathrm{Y}$ (mass\%) master alloy, and pure $\mathrm{Zn}$ were added into the melt at $1073 \mathrm{~K}$. The melt was fully stirred and rested for $15 \mathrm{~min}$, then cooled in water (Alloy I). Table 1 lists the actual chemical compositions of the designed alloys. The ingot was cut and annealed at $813 \mathrm{~K}$ in an atmosphere for $40 \mathrm{~h}$ with different heat treatment parameters, followed by quenching in water (Alloy II) and slowly cooling in furnace (Alloy III), respectively, which are listed in Table 2. 

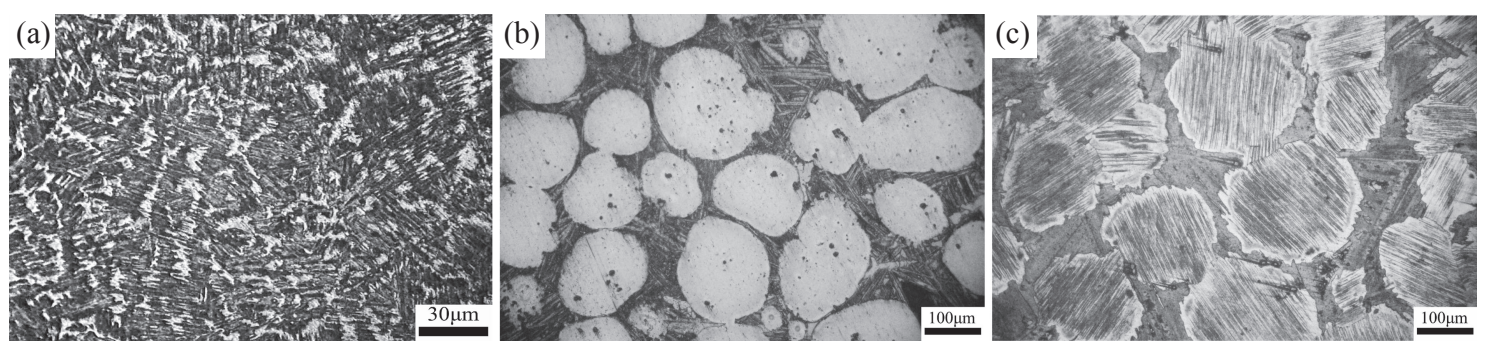

Fig. 1 Optical micrographs of the as-cast Mg-Cu-Mn-Zn-Y series alloys with different morphology distribution: (a) Alloy I, (b) Alloy II, (c) Alloy III.

Table 1 Chemical composition of the $\mathrm{Mg}-3 \mathrm{Cu}-1 \mathrm{Mn}-1.8 \mathrm{Zn}-10 \mathrm{Y}$ alloys (in $\operatorname{mass} \%$ ).

\begin{tabular}{llccccc}
\hline \multirow{2}{*}{$\begin{array}{l}\text { Alloy } \\
\text { code }\end{array}$} & \multirow{2}{*}{\begin{tabular}{c} 
Nominal composition \\
\cline { 3 - 6 }
\end{tabular}} & & \multicolumn{5}{c}{ Actual composition } \\
\cline { 3 - 7 } Alloy I & $\mathrm{Mg}-3 \mathrm{Cu}-1 \mathrm{Mn}-1.8 \mathrm{Zn}-10 \mathrm{Y}$ & $\mathrm{Bal}$ & 2.97 & 1.69 & 1.83 & 11.93 \\
\hline
\end{tabular}

Table 2 The different heat treatment of $\mathrm{Mg}-3 \mathrm{Cu}-1 \mathrm{Mn}-1.8 \mathrm{Zn}-10 \mathrm{Y}$ alloys.

\begin{tabular}{ll}
\hline Alloy code & \multicolumn{1}{c}{ heat treatment process } \\
\hline Alloy I & As-cast \\
Alloy II & $813 \mathrm{~K} 40 \mathrm{~h}$, quenching in water \\
Alloy III & $813 \mathrm{~K} 40 \mathrm{~h}$, cooling in furnace \\
\hline
\end{tabular}

The microstructures of the specimens were examined under an Olympus optical microscope. Phase analysis was carried out at a scanning angle of $20^{\circ}-90^{\circ}$ and a scanning speed of 2 degrees/min, using a Rigaku D/Max2500PC XRD with a copper target. The damping capacity was investigated by a dynamic mechanical analyzer (TA-DMA Q800) with single-cantilever vibration mode. The damping capacity was evaluated by $Q^{-1}=\tan \Phi$, where $\Phi$ was the lag angle between the applied strain and the response stress. The damping test samples of $45 \mathrm{~mm} \times 5 \mathrm{~mm} \times 1.2 \mathrm{~mm}$ were machine-prepared using an electric spark cutter. To determine the dependence of damping capacity on strain, tests were performed over a strain-amplitude $(\varepsilon)$ ranging from $10^{-5}$ to $10^{-3}$ at room temperature and vibration frequency $(f)$ was set to $1 \mathrm{~Hz}$. Each DMA specimen was heated from $300 \mathrm{~K}$ to $673 \mathrm{~K}$ at a constant heating rate of $4.6 \mathrm{~K} / \mathrm{s}$. The testing frequency and strain amplitude were set at $1 \mathrm{~Hz}$ and $4 \times 10^{-4}$, respectively.

\section{Results and Discussion}

\subsection{Microstructures of as-cast alloys}

The optical micrographs in Fig. 1 show the microstructures of the as-cast $\mathrm{Mg}-\mathrm{Cu}-\mathrm{Mn}-\mathrm{Zn}-\mathrm{Y}$ alloys with different morphology distribution. It can be seen from Fig. 1(a) that $\alpha-\mathrm{Mg}$ grains were surrounded by secondary phases which are randomly distributed as dendritic in shape. After solid solution treatment, the grain size of the alloy grows significantly. The second phase in the process of solid solution gradually integrated into the substrate, forming a supersaturated solid solution, the block-shaped phases which
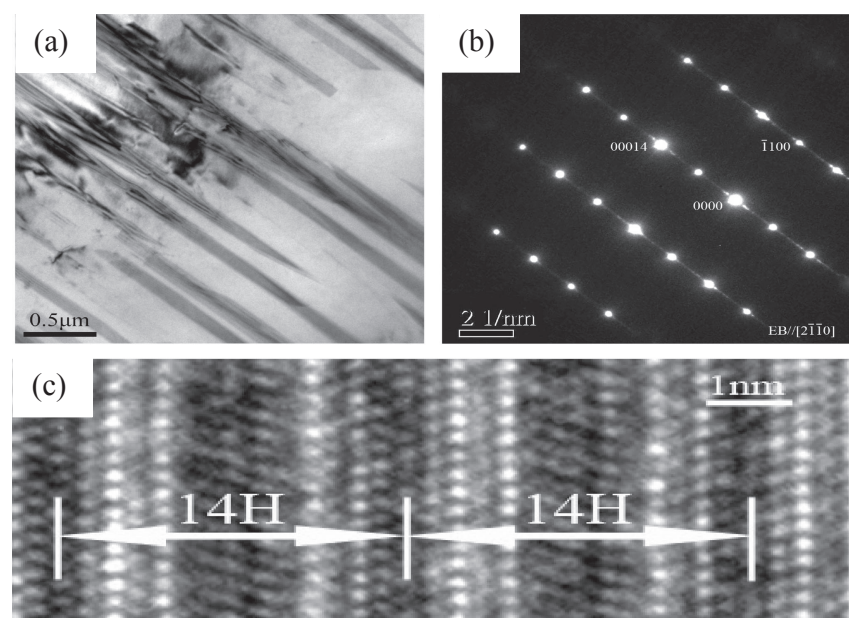

Fig. 2 TEM images of alloy III (a) fine LPSO lamellae, (b) SAED pattern of fine LPSO lamellae, and (c) HREM image of fine LPSO lamellae.

were not yet dissolved completely aggregate at the grain boundaries. As the cooling process, the second phases gradually precipitate from supersaturated grain, the slower the cooling speed, the easier a parallel arrangement and platelike shapes second phase within the grain.

Figure 2 shows TEM images of the lamellar LPSO phase in alloy III. Figure 2(a) shows a bright field TEM image of the lamellar-shaped LPSO phase, which can be easily observed in the optical micrograph shown in Fig. 1(c). The SAED pattern along the [2-1-10] $\alpha$ direction of the $\mathrm{Mg}$ matrix in Fig. 2(b) shows that the distance between the incident spot and the (0002) $\alpha$-Mg spot was divided into 14 equal parts and thus the lamellar-shaped phase was determined to be $14 \mathrm{H}$ type LPSO phase. The high resolution transmission electron microscope (HREM) image of the LPSO phase given in Fig. 2(c) also reveals that $14 \mathrm{H}$ unit cells are obtained to make up the $14 \mathrm{H}$ structure. Upon treatment of the solute at $813 \mathrm{~K}$, some studies show that the $\mathrm{RE}$ and $\mathrm{Zn}$ atoms in the $\mathrm{Mg}_{24}(\mathrm{RE}, \mathrm{Zn})_{5}$ and $(\mathrm{Mg}, \mathrm{Zn})_{3} \mathrm{RE}$ phases diffuse into the matrix whereas the $\mathrm{Mg}_{12} \mathrm{ZnRE}$ phase remains as a gray block phase because that the LPSO phase is relatively stable at high temperatures. ${ }^{12,13)}$ As can be seen from the Fig. 1, alloy II remained the state of the solution after heat treatment, and the second phase is spread to the matrix, forming a supersaturated solid solution, $\mathrm{Mg}$ matrix is greatly increased, and fine particles were dispersed randomly inside the grains. However, since the cooling rate is slow, the second phase re-precipitated throughout all the grains and arranged in parallel-shaped found in alloy III. Therefore, after different 


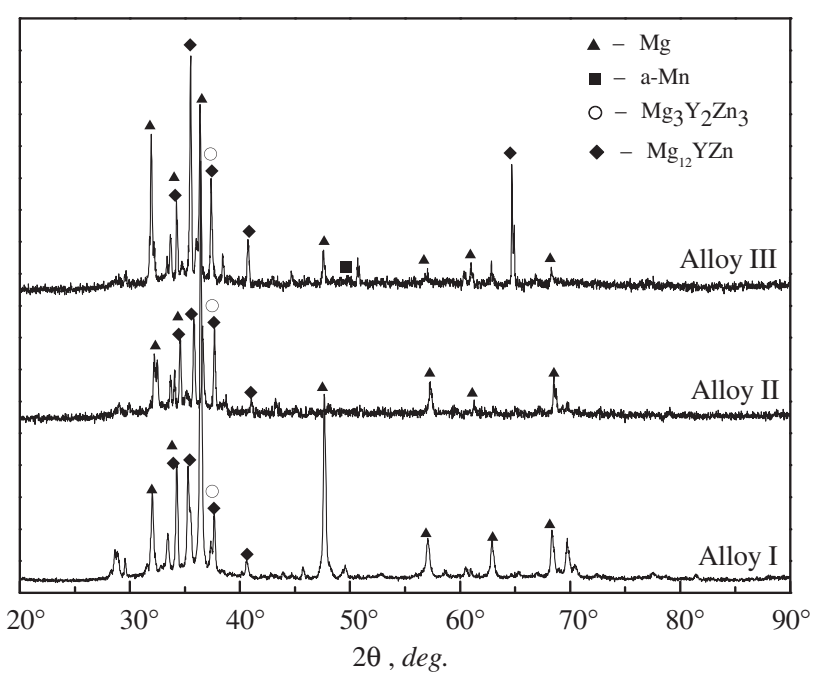

Fig. 3 XRD pattern of the as-cast $\mathrm{Mg}-\mathrm{Cu}-\mathrm{Mn}-\mathrm{Zn}-\mathrm{Y}$ series alloy.

heat treatment, the morphology of the LPSO phases, which are formed by solidification in the as-cast alloy, transforms into the block LPSO phase in grain boundaries and generate the lamellar LPSO phase in the grain interior.

The pattern of the results of X-ray diffraction (XRD) of the as-cast alloy indicates that the main phase composition for alloys consists of $\alpha-\mathrm{Mg}, \alpha-\mathrm{Mn}, \mathrm{Mg}_{12} \mathrm{ZnY}$ phase and $\mathrm{Mg}_{3} \mathrm{Y}_{2} \mathrm{Zn}_{3}$ phase, which is shown in Fig. 3. In addition, the intensity of the $\mathrm{Mg}_{12} \mathrm{ZnY}$ phase diffraction peaks increased with the decrease of the cooling rate. No other phase is detected within the sensitivity limit of the XRD instrument.

\subsection{Strain damping capacities of the as-cast $\mathrm{Mg}-\mathrm{Cu}-$ Mn-Zn-Y alloys}

Figure 4 shows the damping capacities of the as-cast $\mathrm{Mg}$ $\mathrm{Cu}-\mathrm{Mn}-\mathrm{Zn}-\mathrm{Y}$ alloys at $1 \mathrm{~Hz}$ and $308 \mathrm{~K}$. The $\mathrm{x}$-axis and y-axis correspond to the strain amplitude $(\varepsilon)$ and damping capacity $\left(Q^{-1}\right)$, respectively. It can be observed that the damping parameter $Q^{-1}$ value for all alloys increases continuously with the increment of strain amplitude from $1 \times 10^{-5}$ to $3 \times 10^{-3}$. Overall, under lower strain amplitudes, the damping growth of all the alloys is very slow. However, when the strain amplitude surpasses a critical value, damping growth begins to accelerate rapidly. It can be seen from these three strain-amplitude damping curves, damping curve of three kinds of alloys almost overlap at low strain amplitude, and under the high strain amplitude, the damping capacities of alloy III are observed to be better than those of alloy I and alloy II.

Many damping test results of $\mathrm{Mg}$ and $\mathrm{Mg}$ alloys ${ }^{14-17)}$ show that the strain-dependent damping can be divided into two regions. In the first part, in which the strain amplitude is low, the strain amplitude affects little change on the damping value, and no significant changes can be observed among the alloys. However, in the second part, in which the strain amplitude slightly surpasses a critical value, the damping values become markedly different. The damping capacity began to depend strongly on strain amplitude, and damping growth accelerated substantially. The boundary strain amplitude between low strain amplitude weakly dependent part

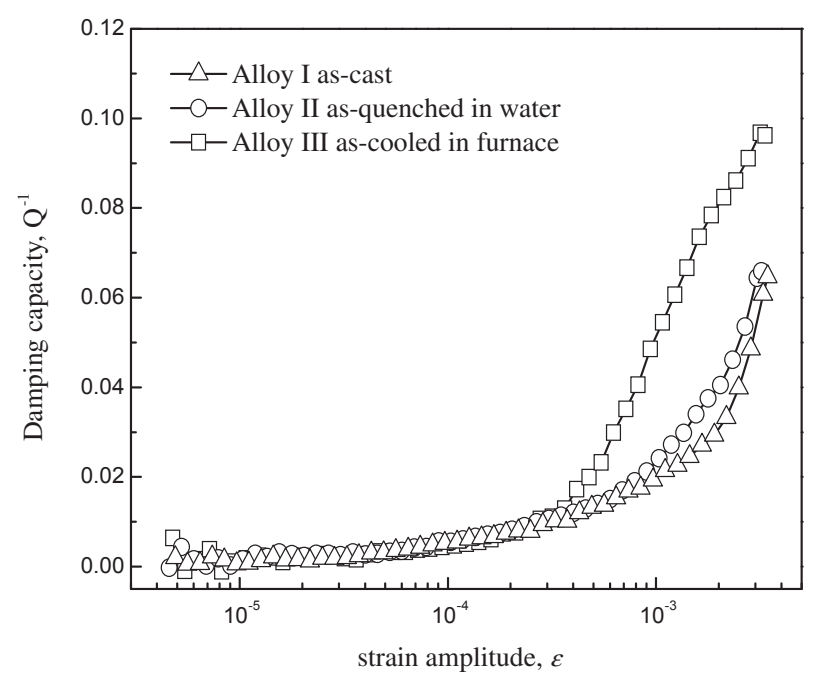

Fig. 4 Damping-strain amplitude curves of as-cast $\mathrm{Mg}-\mathrm{Cu}-\mathrm{Mn}-\mathrm{Zn}-\mathrm{Y}$ series alloys with different morphology LPSO-phase under $\varepsilon$ ranging from $1 \times 10^{-5}$ to $3 \times 10^{-3}$.

Table 3 Damping properties of $\mathrm{Mg}-\mathrm{Cu}-\mathrm{Mn}-\mathrm{Zn}-\mathrm{Y}$ alloys under different conditions.

\begin{tabular}{cccc}
\hline \multirow{2}{*}{ Alloy code } & Morphology & \multicolumn{2}{c}{ Strain Amplitude } \\
\cline { 3 - 4 } & & $1 \times 10^{-4}$ & $1 \times 10^{-3}$ \\
\hline Alloy I & Dendritic grains & 0.0055 & 0.020 \\
Alloy II & Block LPSO & 0.0053 & 0.023 \\
Alloy III & Block LPSO + lamellar LPSO & 0.0047 & 0.052 \\
\hline
\end{tabular}

and high strain amplitude strongly dependent part is called critical strain amplitude, which is mainly determined by the binding energy between the dislocation and the solute atoms and should relate to solute concentration. ${ }^{18)}$ By calculating the average damping value near the turning point of the curve, the corresponding critical strain values of alloys I to III are $1.66 \times 10^{-3}, 1.05 \times 10^{-3}$, and $3.66 \times 10^{-4}$, respectively. The more solute atoms distributing among the dislocation, the more stress to breakaway their interaction force is required, which will cause a bigger critical strain amplitude. The higher cooling rate the alloy is, the larger critical strain and the lower damping capacities the alloy exhibits. From the perspective of morphology, we can conclude that the damping capacities of the three alloys with different phase morphologies follow the trend: block LPSO + lamellar LPSO (alloy III) > block LPSO (alloy II) > dendritic grains (alloy I), which is shown in Table 3.

The damping mechanism of alloys is generally considered to involve dislocation movements, which can be explained by the Granato-Lücke dislocation damping theory. ${ }^{4,5)}$ At low strain amplitude, the movable dislocations are nailed by strong pinning, that they only move between weak pinning as reciprocating motion, thereby generating low internal friction in the alloys. After heat treatment of the alloys, the mass of solute atoms dissolve into the $\alpha-\mathrm{Mg}$ matrix increase the number of weak pinning points. Therefore, alloy II and alloy III show slightly lower damping than alloy I at the lowstrain region. At high strain amplitude, when the strain 

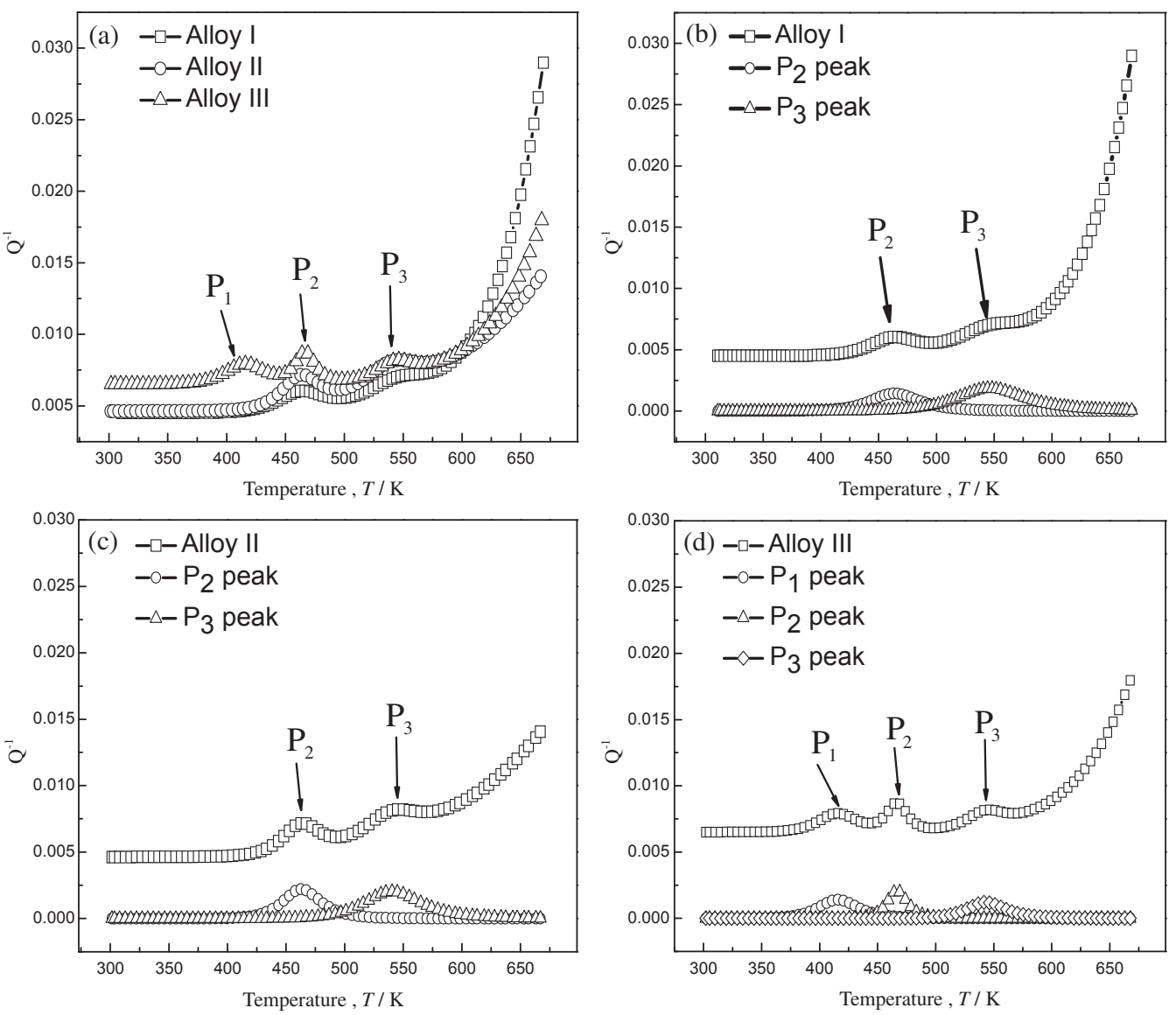

Fig. 5 Temperature-damping curve of heating treatment state $\mathrm{Mg}-\mathrm{Cu}-\mathrm{Mn}-\mathrm{Zn}-\mathrm{Y}$ alloys.

amplitude exceeds a critical value, the dislocations get rid of the weak pinning so that the damping value rapidly increases caused by avalanche of de-nail. For one thing, solution treatment at $813 \mathrm{~K}$ for $40 \mathrm{~h}$ followed by quenching in water causes an increase in the amount of solute atoms so that dislocation or stacking faults are also more likely to be hindered and unable to move. While the sample cooling in furnace, the formation of the lamellar LPSO phase induces a decrease in the amount of solute atoms but also adds the interaction between the dislocation and point obstacles, which maybe induce friction in releasing additional energy, thereby contributing positive effects on the internal friction of the alloys. For another, the lamellar LPSO phase, which also maybe resembles a rough fiber, shows more interfaces with the matrix and moves back and forth more easily to comply with the vibration stress.

\subsection{High temperature damping capacity of the as-cast Mg-Cu-Mn-Zn-Y alloys}

Figure 5(a) shows the heating curve of internal friction $Q^{-1}$ versus temperature in the range from 300 to $673 \mathrm{~K}$ for the $\mathrm{Mg}-\mathrm{Cu}-\mathrm{Mn}-\mathrm{Zn}-\mathrm{Y}$ alloys measured at constant strain amplitude of $4 \times 10^{-4}$ under a heating rate of $4.6 \mathrm{~K} / \mathrm{s}$ and with a frequency of $1 \mathrm{~Hz}$. Obviously, each curve has its own characteristic peaks, especially alloy III has three peaks but alloy I and alloy II has two peaks in the corresponding position, which is fitted for clear peak value in Fig. 5(b), (c), (d). As shown in Fig. 5(b), the spectrum of alloy I exhibits $P_{2}$ and $\mathrm{P}_{3}$ peaks at $466 \mathrm{~K}$ and $548 \mathrm{~K}$, respectively. However, the
Table 4 Temperature-damping peaks of $\mathrm{Mg}-\mathrm{Cu}-\mathrm{Mn}-\mathrm{Zn}-\mathrm{Y}$ with different treatments.

\begin{tabular}{cccc}
\hline Spectra $/ Q^{-1}$ & $\mathrm{P}_{1}$ peak & $\mathrm{P}_{2}$ peak & $\mathrm{P}_{3}$ peak \\
\hline Alloy I & None & 0.00604 & 0.00709 \\
Alloy II & None & 0.00717 & 0.0082 \\
Alloy III & 0.00793 & 0.00865 & 0.00819 \\
\hline
\end{tabular}

spectrum of alloy II and alloy III changed after solid solution treatment. Two peaks, namely, $\mathrm{P}_{2}$ and $\mathrm{P}_{3}$, whose temperature is $462 \mathrm{~K}$ and $545 \mathrm{~K}$, respectively, appear in the second heating $Q^{-1}$ spectrum of alloy II as shown in Fig. 5(c). Figure 5(d) shows the third heating $Q^{-1}$ spectrum of alloy III, which is cooled in furnace. All three peaks change, especially $\mathrm{P}_{1}$, which emerges and is quite conspicuous. The temperatures of each peak were $416 \mathrm{~K}, 464 \mathrm{~K}$, and $546 \mathrm{~K}$, respectively. The damping properties of alloy III, which has lamellar LPSO phase is higher than that of alloy I and alloy II. Table 4 summarizes the information from the spectra of the three alloys.

Peak $\mathrm{P}_{1}$ in the heating $Q^{-1}$ curve of pure magnesium and magnesium alloys is believed to be associated with the movement of the dislocation. ${ }^{19)}$ At the same time, according to the Granato-Lücke dislocation damping theory, ${ }^{4,5)}$ the damping caused by dislocation movement in the low temperature range is direct proportional to the dislocation density and is related to the strain amplitude and vibration frequency. As test parameters which mean strain amplitude, 
loading frequency, temperature range and heating rate are same, peak $\mathrm{P}_{1}$ of the alloy I and alloy II are almost annihilated. Heat treatment which strongly influenced the distribution state of point defects will strongly affect the damping peak. Alloy I and alloy II are supersaturated solid solution which the dislocations were strongly pinned by impurity atoms or vacancies and the peak $\mathrm{P}_{1}$ almost disappeared. The lamellar LPSO phase was from reprecipitating in the matrix to reduce the dislocation obstacles conducive to dislocation movement. Therefore, peak $\mathrm{P}_{1}$ appears in the alloy III.

The $\mathrm{P}_{2}$ peaks in all of three curves have the same peak shape and relatively narrow temperature ranges (466 K, $462 \mathrm{~K}$ and $464 \mathrm{~K}$, respectively). Munitz et al. ${ }^{20)}$ have found that a $Q^{-1}$ peak appears between $423 \mathrm{~K}$ to $473 \mathrm{~K}$ in the heating $Q^{-1}$ curve of as-cast pure magnesium. This peak has obvious characteristics of thermal activation. The authors inferred that it was the grain boundary peak. Therefore, the peak $\mathrm{P}_{2}$ in the present experiment may also be the grain boundary damping peak. The alloy I are almost dendrite and its dendritic spacing is small, the contribution of grain boundary sliding on the damping is small. Both alloy II and alloy III have larger grain size, but the alloy III with the lamellar LPSO phase has more interface in the grain interior, interface slip is also conducive to damping. Another significant peak $\mathrm{P}_{3}$ appears in all of the three heating $Q^{-1}$ curves. A number of researchers are interest in this internal friction peak $\mathrm{P}_{3}$. Wang ${ }^{21)}$ analyzed the heating $Q^{-1}$ curve of as-rolled $\mathrm{Mg}-3 \% \mathrm{Al}$ alloy, and inferred that the peak $\mathrm{P}_{3}$ is a recrystallization peak. Wu et al. found this peak at $\sim 623 \mathrm{~K}$ in as-extruded Grp/AZ91 composite, the position and height of this peak was thought to be attributed to the grain size of material and grain growth behavior during the damping test process. ${ }^{22)}$ As the LPSO phase is a high temperature stable phase, therefore, it infers that this peak could be related to diffusion of the solute atoms.

\section{Conclusions}

$\mathrm{Mg}-3 \mathrm{Cu}-1 \mathrm{Mn}-1.8 \mathrm{Zn}-10 \mathrm{Y}$ (mass\%) alloy was homogenized at $813 \mathrm{~K}$ for $40 \mathrm{~h}$ followed by quenching in water and cooling in furnace. The microstructure and damping properties were investigated and the conclusions are summarized as follows:

(1) Primary dendritic phases were transformed into blockshaped LPSO phase and block-shaped and lamellarshaped $14 \mathrm{H}$ LPSO phases during the solid solution treatment followed by quenching in water and cooling in furnace, respectively.

(2) The damping property of the as-cooled sample with the damping capacity $Q^{-1} \geq 0.052$ at strains exceeding $1 \times 10^{-3}$ after solid solution treatment were improved compared with that of the as-cast alloy and the asquenched sample. From the diversity of the damping capacities of alloys with various morphologies, we can conclude that the appearance of the lamellar LPSO phase is more conducive to the damping capacity.

(3) At the testing temperature of $300 \mathrm{~K}$ to $673 \mathrm{~K}$, the ascooled sample exhibits the best high temperature damping capacity, the reasons can be attributed to the coarse grains, abundant interfaces and interfacial slipping caused by the lamellar LPSO phases.

\section{Acknowledgements}

The authors are grateful for the financial support from the foundation support of the Key Laboratory of Science and Technology on High Energy Laser, CAEP, the State Key Laboratory of Mechanical Transmission-Chongqing University (Grant No. SKLMT-ZZKT-2012 MS), the National Natural Science Foundation Commission of China (Grant No. 51271206), and the National Basic Research Program of China (Grant No. 2013CB632201).

\section{REFERENCES}

1) B. L. Mordike: Mater. Process. Technol. 117 (2001) 391-394.

2) L. Zheng, C. M. Liu, Y. C. Wan, P. W. Yang and X. Shu: J. Alloy. Compd. 509 (2011) 8832-8839.

3) C. Xu, M. Y. Zheng, S. W. Xu, K. Wu, E. D. Wang, S. Kamado, G. J. Wang and X. Y. Lv: Mater. Sci. Eng. A 547 (2012) 93-98.

4) A. Granato and K. Lücke: J. Appl. Phys. 27 (1956) 583.

5) A. Granato and K. Lücke: J. Appl. Phys. 27 (1956) 789.

6) X. Zeng, Y. Zhang, C. Lu, W. Ding, Y. Wang and Y. Zhu: J. Alloy. Compd. 395 (2005) 213.

7) A. Singh and A. P. Tsai: Scr. Mater. 49 (2003) 143.

8) M. Yamasaki, M. Sasaki, M. Nishijima, K. J. Hiraga and Y. Kawamura: Acta Mater. 55 (2007) 6798-6805.

9) A. Inoue, Y. Kawamura, M. Matsushita, K. Hayashi and J. Koike: J. Mater. Res. 16 (2001) 1894-1900.

10) J. F. Wang, R. P. Lu, W. W. Wei, X. F. Huang and F. S. Pan: J. Alloy. Compd. 537 (2012) 1-5.

11) K. Sugimoto, K. Niiya, T. Okamoto and K. Kishitake: Trans. JIM 18 (1977) 277-288.

12) Y. M. Zhu, A. J. Morton and J. F. Nie: Acta Mater. 58 (2010) 29362947.

13) A. Datta, U. V. Waghmare and U. Ramamurty: Acta Mater. 56 (2008) 2531-2539.

14) Z. Trojanová, P. Lukáč, W. Riehemann and B. L. Mordike: Mater. Sci. Eng. A 324 (2002) 122-126.

15) K. Nishiyama, R. Matsuib, Y. Ikedab, S. Niwac and T. Sakaguchi: J. Alloy. Compd. 355 (2003) 22-25.

16) O. A. Lambri, W. Riehemann, E. J. Lucioni and R. E. Bolmaro: Mater. Sci. Eng. A 442 (2006) 476.

17) J. F. Wang, Z. S. Wu, S. Gao, R. P. Lu, D. Z. Qin, W. X. Yang and F. S. Pan: J. Magn. Alloys 3 (2015) 79-85.

18) D. Q. Wan, J. C. Wang and G. C. Yang: Mater. Sci. Eng. A 517 (2009) 114.

19) M. Y. Zheng, G. D. Fan, L. B. Tong, X. S. Hu and K. Wu: Trans. Nonferrous Met. Soc. China 18 (2008) s33-s38.

20) A. Munitz, D. Dayan and R. Ricker: Magn. Technol. 12 (2004) 103106.

21) S. C. Wang: Effect of Rolling Process on Damping Capacity and Mechanical Properties of Mg-3\%Al Alloy, Harbin, Harbin Institute of Technology, (2009) pp. 46-56.

22) Y. W. Wu, K. Wu, K. K. Deng, K. B. Nie, X. J. Wang, X. S. Hu and M. Y. Zheng: Mater. Sci. Eng. A 527 (2010) 6816-6821. 